\title{
On Enterprise Information System Research Trend-Based on the Keywords Frequency Analysis of Journal EIS 2007-2015
}

\author{
Jiangping Wan, Qiaowen Jiang \\ School of Business Administration, South China University of Technology, Guangzhou, China \\ Email: csjpwan@scut.edu.cn, 136934756@qq.com
}

Received 17 March 2016; accepted 18 April 2016; published 21 April 2016

Copyright $@ 2016$ by authors and Scientific Research Publishing Inc.

This work is licensed under the Creative Commons Attribution International License (CC BY). http://creativecommons.org/licenses/by/4.0/

(c) (i) Open Access

\section{Abstract}

The journal of Enterprise Information Systems (EIS) was founded in 2007 by Taylor \& Francis, selected by the Web of Science Citation Index Expanded in 2008, and included in EI. The research collects 219 papers published in the EIS from 2007 to 2015, and explores valuable information such as the present situation and hotspot trends in the research of the enterprise information systems by extracting and analyzing the keyword of those papers. Finally, we analyze and comment on 9 related papers with considering the trends: enterprise architecture, cloud computing services, ontology and semantic, data science and social networking, enterprise integration and systems science. The research can help relevant scholars to understand EIS research situation, and have a mind to EIS research trends.

\section{Keywords}

Enterprise Information System, Keywords Frequency Analysis, Enterprise Architecture, Cloud Computing Services, Ontology and Semantic, Data Science, Social Network, System Science, Enterprise Integration

\section{Introduction}

This article is based on papers data published on the journal of Enterprise Information Systems (EIS) during 2007 to 2015; the research hotspots and the trends in the development of EIS systems are analyzed with word frequency [1]. We hope the research can help relevant scholars to understand EIS research situation, and have a mind to EIS research trends.

The main research field is enterprise information systems; according to the document rule of dispersion, a 
handful of core journals usually contain critical documents in the field, so this research collects 233 references that were collected by EIS from 2007 to 2015. There are 219 effective references without literature review and editoral comment. Every year total amount and effective number of literature are illustrated in Table 1 . All data of title, author, literature source, keywords and so on are gathered as the sample; we sort the keywords according to the frequency, and carry through related analysis after filtered the keywords.

This paper is structured in the following: Section 2 is word frequency analysis, including keyword filtering merge, hot keywords, and variation conditions of hot keyword. Section 3 discusses on EIS research trends, including comments on nine related papers in five areas as following: enterprise architecture, cloud computing services, ontology and semantic, data science and social networking, enterprise integration and systems science. Section 4 is the conclusions.

\section{Word Frequency Analysis}

\subsection{Keyword Filtering Merge}

The research merges filter processing the keywords as Table 2, for example, the keyword "semantic", "semantic similarity", "semantic integration" can be incorporated into the "semantic" item, etc.

\subsection{Hot Keyword}

The 210 articles are analyzed by keyword frequency statistics, we obtain a total of 1287 keywords, extracted the keywords which appeared exceed five as outstanding performance of the emphasis and future research trend of the development in the enterprise information system domain. Finally, 26 keywords are selected (Table 3). Those keywords illustrate some obvious characteristics, such as: 1) Keywords in the keyword table attributes can be into two categories that object of study, research method and tool; 2) Research method and tool can be divided into technical attributes and management properties Technical attributes method such as data mining, Radio frequency identification (RFID) and information technology, management properties method contains supply chain management and enterprise architecture, etc.; 3) According to the discipline characteristic analysis, it's obvious that those keywords mainly concentrated in four major fields as follow: enterprise information systems (EIS), enterprise resource planning (ERP), business process, and web service.

\subsection{Variation Conditions of Hot Keyword}

The top 10 keywords in every year are illustrated in Tables 4(a)-(c).

The findings are illustrated in Tables 4(a)-(c) as follow: 1) EIS, ERP as keywords have been among the top 10 keywords ranking; 2) Followed after is business process, Web service, SOA, workflow and QoS etc., those keywords belong to research method and object attribute; 3) The e-business doesn't be listed in Tables 4(a)-(c), but it has been popular in recent years, there are still relevant research literatures every year; 4) Cloud Computing Services and CMfg began to emerge in 2012.

We divide time to three periods as follow: 2007-2009, 2010-2012, 2013-2015. The keyword frequency statistics changes in each period are illustrated in the Table 5, at the same time, we can discover the change of the keywords into five categories: smooth (S), growth (G), decline (D), first increase after decreased (FID), first drop after increased (FDI) (Table 6).

\section{Discussion on Enterprise Information System Research Trend}

Based on both our understanding and word frequency analysis, we select the nine related papers to discuss on

Table 1. Literature volume and effective number of papers published on enterprise information systems.

\begin{tabular}{|c|c|c|c|c|c|c|c|c|c|c|}
\hline & \multicolumn{10}{|c|}{ Year } \\
\hline & 2007 & 2008 & 2009 & 2010 & 2011 & 2012 & 2013 & 2014 & 2015 & Tota \\
\hline $\begin{array}{c}\text { The total amount } \\
\text { of literature }\end{array}$ & 25 & 25 & 20 & 20 & 25 & 23 & 27 & 29 & 39 & 233 \\
\hline $\begin{array}{c}\text { Effective number } \\
\text { of papers }\end{array}$ & 24 & 23 & 20 & 19 & 24 & 22 & 24 & 28 & 35 & 219 \\
\hline
\end{tabular}


Table 2. Keyword filtering merging.

\begin{tabular}{|c|c|}
\hline After & Before \\
\hline Petri Net & Petri Net/Logic petri nets/Colored petri net/Tag time petri net \\
\hline $\begin{array}{l}\text { Enterprise Resource } \\
\text { Planning (ERP) }\end{array}$ & $\begin{array}{l}\text { ERP/ERP project/Integration ERP/ERP system/ERP implementation/industry oriented } \\
\text { ERP/ERP/ERPII/ERP life cycle/development of ERP/ERP system performance }\end{array}$ \\
\hline $\begin{array}{c}\text { Cloud } \\
\text { Manufacturing (CMfg) }\end{array}$ & CMfg/CMfg service platform/CMfg services \\
\hline $\begin{array}{l}\text { Service-Oriented } \\
\text { Architecture (SOA) }\end{array}$ & Service-oriented architecture/SOA/Enterprise Service-oriented architecture (ESOA) \\
\hline E-Business & $\begin{array}{l}\text { e-business/e-commerce/e-commerce transaction network/e-commerce system/e-commerce } \\
\text { quality/e-commerce composition }\end{array}$ \\
\hline $\begin{array}{l}\text { Cloud Computing } \\
\text { Services }\end{array}$ & Cloud services/Cloud Computing/Cloud Computing Services platform/Public cloud \\
\hline Semantic & Semantic/semantic integration/Semantic net/Semantic similarity/Semantic business process management \\
\hline Business Process & $\begin{array}{l}\text { Business Process innovation/Business Process development/Business Process analysis/Business Process } \\
\text { reengineering/Business Process information Business Process transformation/Business Process } \\
\text { management (BPM)/BPM system/Business Process Modeling/Business process modeling notation } \\
\text { (BPMN)/Business process modeling language (UML)/Business process model/Business process mapping }\end{array}$ \\
\hline $\begin{array}{l}\text { Enterprise Information } \\
\text { Systems (EIS) }\end{array}$ & EIS/EIS integration/EIS modeling/EIS design/EIS upgrade project/EIS of financial industry/Enterprise systems \\
\hline Work Flow & $\begin{array}{c}\text { Work flow/Work flow analysis/Work flow management/Work flow process model/Work flow model/Work flow } \\
\text { perspective/Work flow dimension/Work flow constraint/Inter-enterprise work flow }\end{array}$ \\
\hline Quality of Service (QoS) & QoS agent/QoS model/QoS constraint/QoS registration/TxQoS \\
\hline Web Service & $\begin{array}{l}\text { Web 2.0/Web service/QoS of Web service/Web service notification/Web } \\
\text { service selection/Web service Composition }\end{array}$ \\
\hline $\begin{array}{c}\text { Information } \\
\text { Technology (IT) }\end{array}$ & IT professional/manager/IT/Information and communication technology/IT governance (ITG) \\
\hline $\begin{array}{l}\text { Radio Frequency } \\
\text { Identification (RFID) }\end{array}$ & RFID/RFID cost/RFID advantage/RFID challenge \\
\hline Interoperability & Interoperability/Interoperability Framework/Interoperability requirements/inter-enterprise Interoperability \\
\hline $\begin{array}{c}\text { Supply Chain } \\
\text { Management (SCM) }\end{array}$ & Supply chain operation reference (SCOR) model/SCM \\
\hline Product & $\begin{array}{l}\text { Product presentation/Product map/Product processing/Product development/Product } \\
\text { optimization/Products target/Product data management/Product data integration }\end{array}$ \\
\hline
\end{tabular}

enterprise information systems research trends in the following five areas: enterprise architecture, cloud computing services, ontology and semantic, data science and social networking, enterprise integration and system science.

\subsection{Enterprise Architecture}

O. Erol, B. J. Sauser \& M. Mansouri propose a framework for investigation into "extended enterprise resilience" based on the key attributes of enterprise resilience in the context of extended enterprises. The proposed framework is based on the expanded application of two primary enablers of enterprise resilience: 1) the capability of an enterprise to connect systems, people, processes and information in a way that allows enterprise to become more connected and responsive to the dynamics of its environment, stakeholders and competitors; 2) the alignment of information technology with business goals. The former requires inter- and intra-level interoperability and integration within the extended enterprises, and the latter requires modeling of the underlying technology 
Table 3. Hot keywords that frequency exceed 5 distribution.

\begin{tabular}{lccccccccc}
\hline $\mathbf{N}$ & Keyword & F & $\mathbf{P}$ & $\mathbf{C}$ & $\mathbf{N}$ & Keyword & F & P & C (\%) \\
$\mathbf{1}$ & EIS & 64 & 5 & 5 & $\mathbf{1 4}$ & Enterprise architecture & 9 & 0.7 & 22.8 \\
$\mathbf{2}$ & Business Process & 39 & 3 & 8 & $\mathbf{1 5}$ & Semantic & 8 & 0.6 & 23.4 \\
$\mathbf{3}$ & ERP & 37 & 2.9 & 10.9 & $\mathbf{1 6}$ & Cloud manufacturing & 8 & 0.6 & 24 \\
$\mathbf{4}$ & Web Service & 20 & 1.6 & 12.4 & $\mathbf{1 7}$ & Cloud Computing Services & 7 & 0.5 & 24.6 \\
$\mathbf{5}$ & Work Flow & 20 & 1.6 & 14 & $\mathbf{1 8}$ & Data mining & 7 & 0.5 & 25.1 \\
$\mathbf{6}$ & E-business & 19 & 1.5 & 15.5 & $\mathbf{1 9}$ & Service composition & 6 & 0.5 & 25.6 \\
$\mathbf{7}$ & SOA & 18 & 1.4 & 16.9 & $\mathbf{2 0}$ & Dependability & 6 & 0.5 & 26 \\
$\mathbf{8}$ & Interoperability & 14 & 1.1 & 17.9 & $\mathbf{2 1}$ & Enterprise Application & 6 & 0.5 & 26.5 \\
$\mathbf{9}$ & SCM & 13 & 1 & 19 & $\mathbf{2 2}$ & RFID & 6 & 0.5 & 27 \\
$\mathbf{1 0}$ & Quality of Service & 12 & 0.9 & 19.9 & $\mathbf{2 3}$ & Information technology & 6 & 0.5 & 27.4 \\
$\mathbf{1 1}$ & Petri net & 10 & 0.8 & 20.7 & $\mathbf{2 4}$ & Enterprise integration & 5 & 0.4 & 27.8 \\
$\mathbf{1 2}$ & Ontology & 9 & 0.7 & 21.4 & $\mathbf{2 5}$ & Material flow & 5 & 0.4 & 28.2 \\
$\mathbf{1 3}$ & Product & 9 & 0.7 & 22.1 & $\mathbf{2 6}$ & Project Management & 5 & 0.4 & 28.6 \\
\hline
\end{tabular}

Note: N: Number, P: Percent, F: Frequency, C: Cumulative percentage, EIS: Enterprise information systems, SOA: Service-oriented architecture, SCM: Supply Chain Management, RFID: Radio frequency identification, ERP: Enterprise resource planning.

infrastructure and creation of a consolidated view of, and access to, all available resources in the extended enterprises that can be attained by well-defined enterprise architecture [2]. In our understanding, enterprise resilience may be key attribute in Internet age, and the Internet enterprise framework should be focus on its business goal with the capability of an enterprise to connect systems, people, processes and information.

J. M. D. S. Fradinho argues that enterprise systems (ES) is gradually evolving towards a sense of design which leverages multidisciplinary bodies of knowledge that may bolster hybrid research designs and together further the characterization of ES operation and performance. The research aims to contribute towards ES design theory with its hospital enterprise systems design framework, which reflects a rich multidisciplinary literature and two in-depth hospital empirical cases from the US and UK. The research concludes that hospital performance can be improved through an enriched understanding of hospital ES design [3]. In our understanding, so do other organizations, especial in service industry. The ES design research should be towards high performing in the Internet age.

\subsection{Cloud Computing Service}

L. Zhang, Y. L. Luo, F. Tao, B. H. Li, L. Ren, X. S. Zhang, H. Guo, Y. Cheng, A. R. Hu \& Y. K. Liu combine with the emerged technologies such as cloud computing, the Internet of things, service-oriented technologies and high performance computing, a new manufacturing paradigm -CMfg- for solving the bottlenecks in the informatisation development and manufacturing applications. The concept of CMfg, including its architecture, typical characteristics and the key technologies for implementing a CMfg service platform, is discussed. Three core components for constructing a CMfg system, i.e. CMfg resources, manufacturing cloud service and manufacturing cloud are studied, and the constructing method for manufacturing cloud is investigated [4]. In our understanding, emerged technologies such as cloud computing, and the Internet of thing will play more and more action in Internet + and Chinese manufacturing 2025, it’s just a beginning.

\subsection{Ontology and Semantic}

F. Dagka, K. Papadaki, G. Lepouras \& C. Vassilakis argue that the wiki technology is increasingly being used in corporate environments to facilitate a broad range of tasks. They examines the use of wikis on a variety of organizational tasks that include the codification of explicit and tacit organizational knowledge and the formulation of corporate communities of practice, as well as more specific processes such as the collaborative information 
Table 4. (a) The top 10 keywords are illustrated in every year from 2007 to 2009; (b) The top 10 keywords are illustrated in every year from 2010 to 2012; (c) The top 10 keywords are illustrated in every year from 2013 to 2015.

(a)

\begin{tabular}{|c|c|c|c|c|c|c|c|c|}
\hline 2007 & & & 2008 & & & 2009 & & \\
\hline Keyword & $\mathrm{F}$ & $\mathrm{P}$ & Keyword & $\mathrm{F}$ & $\mathrm{P}$ & Keyword & $\mathrm{F}$ & $\mathrm{P}$ \\
\hline EIS & 12 & 6.7 & Business process & 12 & 8.7 & SOA & 6 & 5.4 \\
\hline E-business & 8 & 4.5 & EIS & 7 & 5.1 & EIS & 6 & 5.4 \\
\hline Work flow & 5 & 2.8 & ERP & 4 & 2.9 & Web service & 5 & 4.5 \\
\hline SCM & 5 & 2.8 & Work flow & 3 & 2.2 & Product & 4 & 3.6 \\
\hline ERP & 5 & 2.8 & Ptri Net & 3 & 2.2 & ERP & 4 & 3.6 \\
\hline Enterprise integration & 4 & 2.2 & Web service & 2 & 1.4 & Dependability & 3 & 2.7 \\
\hline Business process & 4 & 2.2 & QoS & 2 & 1.4 & Business process & 3 & 2.7 \\
\hline E-market & 3 & 1.7 & Dependability & 2 & 1.4 & SaaS & 2 & 1.8 \\
\hline $\begin{array}{l}\text { Inter-organizational and } \\
\text { intra-organizational } \\
\text { information system }\end{array}$ & 3 & 1.7 & SOA & 2 & 1.4 & Character & 2 & 1.8 \\
\hline XPMF & 2 & 1.1 & Enterprise Modeling & 2 & 1.4 & BPELlig & 1 & 0.9 \\
\hline
\end{tabular}

Note: N: Number, P: Percent, F: Frequency, C: Cumulative percentage, SOA: Service-oriented architecture, EIS: Enterprise resource planning, ERP: Enterprise resource planning, SCM: Supply Chain Management, QoS: Quality of Service, XPMF: X Party Material Flow.

(b)

\begin{tabular}{|c|c|c|c|c|c|c|c|c|}
\hline \multicolumn{3}{|c|}{2010} & \multicolumn{3}{|l|}{2011} & \multicolumn{3}{|l|}{2012} \\
\hline Keyword & $\mathrm{F}$ & $\mathrm{P}$ & Keyword & $\mathrm{F}$ & $\mathrm{P}$ & Keyword & $\mathrm{F}$ & $\mathrm{P}$ \\
\hline ERP & 6 & 4.8 & EIS & 9 & 6.3 & service composition & 3 & 2.4 \\
\hline QoS & 5 & 4 & SCM & 4 & 2.8 & Work flow & 3 & 2.4 \\
\hline EIS & 5 & 4 & RFID & 4 & 2.8 & EIS & 3 & 2.4 \\
\hline Resilience & 3 & 2.4 & Computer-aided design & 3 & 2.1 & ERP & 3 & 2.4 \\
\hline Business process & 3 & 2.4 & Petri Net & 3 & 2.1 & Web service & 2 & 1.6 \\
\hline Web service & 2 & 1.6 & Data mining & 3 & 2.1 & Ontology & 2 & 1.6 \\
\hline Cost Estimating & 2 & 1.6 & Business process & 3 & 2.1 & Product & 2 & 1.6 \\
\hline E-business & 2 & 1.6 & SOA & 2 & 1.4 & Multi-discipline design & 2 & 1.6 \\
\hline Dependability & 2 & 1.6 & Enterprise architecture & 2 & 1.4 & Dependability & 2 & 1.6 \\
\hline Fault Tolerance & 2 & 1.6 & ERP & 2 & 1.4 & Combined relationship & 2 & 1.6 \\
\hline
\end{tabular}

Note: N: Number, P: Percent, F: Frequency, C: Cumulative percentage, SOA: Cumulative percentage, Service-oriented architecture, EIS: Enterprise resource planning, ERP: Enterprise resource planning, SCM: Supply Chain Management, QoS: Quality of Service, RFID: Radio frequency identification.

(c)

\begin{tabular}{ccccccccc}
\hline \multicolumn{2}{c}{$\mathbf{2 0 1 3}$} & & \multicolumn{2}{c}{$\mathbf{2 0 1 4}$} & \multicolumn{2}{c}{$\mathbf{2 0 1 5}$} \\
\hline Keyword & $\mathrm{F}$ & $\mathrm{P}$ & Keyword & $\mathrm{F}$ & $\mathrm{P}$ & Keyword & $\mathrm{F}$ & $\mathrm{P}$ \\
Work flow & 6 & 4.7 & EIS & 7 & 4.7 & EIS & 10 & 5.2 \\
EIS & 5 & 3.9 & ERP & 7 & 4.7 & Interoperability & 6 & 3.1 \\
Web service & 3 & 2.3 & Business process & 5 & 3.4 & E-business & 5 & 2.6 \\
IIIE & 2 & 1.6 & Semantic & 5 & 3.4 & Business process & 5 & 2.6 \\
Parallel & 2 & 1.6 & CMfg & 5 & 3.4 & SOA & 4 & 2.1 \\
Framework & 2 & 1.6 & Web service & 3 & 2 & ERP & 4 & 2.1 \\
Enterprise architecture & 2 & 1.6 & Case study & 2 & 1.4 & Cloud Computing Services & 4 & 2.1 \\
ERP & 2 & 1.6 & Service integration & 2 & 1.4 & Ontology & 3 & 1.6 \\
Business process & 2 & 1.6 & KPI & 2 & 1.4 & Service Discovery & 2 & 1 \\
k-anonymity & 1 & 0.8 & B2MML & 1 & 0.7 & QoS & 2 & 1 \\
\hline
\end{tabular}

Note: N: Number, P: Percent, F: Frequency, C: Cumulative percentage, SOA: Cumulative percentage, Service-oriented architecture, EIS: Enterprise resource planning, ERP: Enterprise resource planning, SCM: Supply Chain Management, QoS: Quality of Service, RFID: Radio frequency identification, KPI: Key Performance Indicator, CMfg: Cloud manufacturing. 
Table 5. Hot keywords cycle frequency distribution table.

\begin{tabular}{|c|c|c|c|}
\hline Keyword & 2007-2009 & 2010-2012 & 2013-2015 \\
\hline Enterprise information systems & 25 & 17 & 22 \\
\hline Enterprise resource planning & 13 & 11 & 13 \\
\hline Business Process & 19 & 8 & 12 \\
\hline Web service & 8 & 5 & 7 \\
\hline Work flow & 8 & 4 & 8 \\
\hline Service-oriented architecture & 9 & 3 & 6 \\
\hline Quality of Service & 3 & 6 & 3 \\
\hline Petri net & 3 & 3 & 4 \\
\hline Supply Chain Management & 6 & 5 & 2 \\
\hline e-business & 10 & 3 & 6 \\
\hline Interoperability & 6 & 2 & 6 \\
\hline Ontology & 1 & 4 & 4 \\
\hline Product & 4 & 3 & 2 \\
\hline Semantic & 1 & 1 & 6 \\
\hline Enterprise architecture & 1 & 4 & 4 \\
\hline Data mining & 1 & 4 & 2 \\
\hline Cloud Computing Services & 0 & 1 & 6 \\
\hline Cloud manufacturing & 0 & 1 & 7 \\
\hline
\end{tabular}

Table 6. The type of keyword change trends.

\begin{tabular}{cc}
\hline Type & Keyword \\
\hline G & Ontology, Semantic, Enterprise architecture, Cloud computing services, Cloud manufacturing (CMfg) \\
S & Enterprise resource planning (ERP), Web service, Petri net \\
D & Product, Supply chain management (SCM) \\
FID & Quality of Service (QoS), Data mining \\
FDI & Enterprise information systems (EIS), Business process, Work flow, \\
& E-business, Service-oriented architecture (SOA), Interoperability
\end{tabular}

Note: Smooth (S), growth (G), decline (D), first increase after decreased (FID), first drop after increased (FDI).

systems development, the interactions of the enterprise with third parties, management activities and organizational response in crisis situations. For each one of the aforementioned corporate functions, the study examines the findings of related research literature to highlight the advantages and concerns raised by the wiki usage and to identify specific solutions addressing them [5]. In our understanding, wiki is application of ontology and semantic in the nature. we should pay much attention to wiki in enterprise settings, because wiki will have important on explicit and tacit organizational knowledge and the formulation of corporate communities of practice, and the Internet enterprises will more and more apply wiki technology in 21 century.

\subsection{Data Science and Social Networking}

Y. Q. Xia, W. F. Su, R. Y. K. Lau \& Y. Liu argue that unlike most online social networks where explicit links among individual users are defined, the relations among commercial entities (e.g. firms) may not be explicitly declared in commercial Web sites. One main contribution of the research is the development of a novel computational model for the discovery of the latent relations among commercial entities from online financial news. 
More specifically, a CRF model which can exploit both structural and contextual features is applied to commercial entity recognition. In addition, a point-wise mutual information (PMI)-based unsupervised learning method is developed for commercial relation identification. To evaluate the effectiveness of the proposed computational methods, a prototype system called CoNet has been developed. Their experimental results confirm that the proposed shallow natural language processing methods are effective for the discovery of latent commercial networks from online financial news [6]. In our understanding, data science will become more and more popular for emerged technologies such as cloud computing, and the Internet of thing. Big data analytics in business environments is also just a beginning.

W. Sh. Hu, Zh. G. Gong, L. Hou U \& J. Zh. Guo argue that nowadays social network services have been popularly used in electronic commerce systems. Users on the social network can develop different relationships based on their common interests and activities. In order to promote the business, it is interesting to explore hidden relationships among users developed on the social network. Such knowledge can be used to locate target users for different advertisements and to provide effective product recommendations. They define and study a novel community detection problem that is to discover the hidden community structure in large social networks based on their common interests. They observe that the users typically pay more attention to those users who share similar interests, which enable a way to partition the users into different communities according to their common interests. They propose two algorithms to detect influential communities using common interests in large social networks efficiently and effectively [7]. In our understanding, social networks and community research will be more and more popular in the future for many electronic commerce systems, such as Amazon, Alibaba, Facebook and Twitter, have provided services which allow users to form social networks to share and disseminate their ideas and views about items through the systems.

\subsection{Enterprise Integration and System Science}

G. Gajic, S. Stankovski, G. Ostojic, Z. Tesic \& L. Miladinovic argue that there is a real need for an evaluation of the influence of ERP on the company's performance indicators. They propose an advanced model for the evaluation of the success of ERP implementation on organizational and operational performance indicators in oil-gas companies. The recommended method establishes a correlation between a process-based method, a scorecard model and ERP critical success factors [8]. In our understanding, ERP implementation is enterprise integration in the nature, how to evaluation of the success of ERP implementation remains to research with multidisciplinary in the future, especial in the Internet age.

J. N. Warfield argues that enterprise integration is a major global challenge of these times. It is now possible for a new generation of practitioners to engage this challenge selectively by applying a recently articulated version of systems science (WSS). J. N. Warfield argues that a half-century of disarray of the systems field can be seen as ending; and that the distillation of WSS to support a wide variety of application areas (in this instance, enterprise integration) can occupy practitioners as they harness the work program of complexity (WPOC) selectively. Carrying out the WPOC yields predictable portfolio components, consisting of a well-defined mix of tangible and intangible products. The three causes of poor intellectual productivity identified by Kenneth Boulding are nullified when appropriate role matching is achieved between WSS and enterprise integration [9]. In our understanding, enterprise integration should be guided with systems science, we should pay attention to both WSS and WPOC in the future.

J. P. Wan \& J. D. Jones argue that the WSS supports a wide variety of application areas, and is useful to practitioners who use the WPOC tool. WPOC is applied to information technology service management (ITSM) for managing the complexity of projects [10]. In our understanding, this is the first time to apply the WSS to an ITSM project implementation. Not only is it novel to apply WSS to ITSM, but also this is beneficial to the furtherance of the field. This helps to gain some insight about the interplay between these two methodologies.

\section{Conclusion}

The research collects 219 papers published in journal of enterprise information systems from 2007 to 2015, and explores valuable information such as the present situation and hotspot trends in the research of the enterprise information systems with extracting and analyzing the keywords of those papers. We find that those keywords mainly concentrate in four major fields as follows: enterprise information systems, enterprise resource planning, business process, and web service. The top 10 keywords in every year and hot keywords' cycle frequency dis- 
tribution are illustrated according to three periods. Finally, we select the nine relate papers to discuss on enterprise information systems' research trends in the following five areas: enterprise architecture, cloud computing services, ontology and semantic, data science and social networking, enterprise integration and system science.

\section{References}

[1] Liang, L.M. and Xie, C.X. (2003) Investigation of China's Nanotechnology Study Based on Frequency Analysis of Keywords. Studies in Science of Science, 21, 138-142. (In Chinese)

[2] Erol, O., Sauser, B.J. and Mansouri, M. (2010) A Framework for Investigation into Extended Enterprise Resilience. Enterprise Information Systems, 4, 111-136. http://dx.doi.org/10.1080/17517570903474304

[3] Fradinho, J.M.D.S. (2014) Towards High Performing Hospital Enterprise Systems: An Empirical and Literature Based Design Framework. Enterprise Information Systems, 8, 355-390. http://dx.doi.org/10.1080/17517575.2013.850746

[4] Zhang, L., Luo, Y.L., Tao, F., Li, B.H., Ren, L., Zhang, X.S., Guo, H., Cheng, Y., Hu, A.R. and Liu, Y.K. (2014) Cloud Manufacturing: A New Manufacturing Paradigm. Enterprise Information Systems, 8, 167-187. http://dx.doi.org/10.1080/17517575.2012.683812

[5] Lykourentzou, I., Dagka, F., Papadaki, K., Lepouras, G. and Vassilakis, C. (2012) Wikis in Enterprise Settings: A Survey. Enterprise Information Systems, 6, 1-53. http://dx.doi.org/10.1080/17517575.2011.580008

[6] Xia, Y.Q., Su, W.F., Lau, R.Y.K. and Liu, Y. (2013) Discovering Latent Commercial Networks from Online Financial News Articles. Enterprise Information Systems, 7, 303-333. http://dx.doi.org/10.1080/17517575.2011.621093

[7] Hu, W.Z., Gong, Z.G., Hou U, L. and Guo, J.Z. (2015) Identifying Influential User Communities on the Social Network. Enterprise Information Systems, 9, 709-724. http://dx.doi.org/10.1080/17517575.2013.804586

[8] Gajic, G., Stankovski, S., Ostojic, G., Tesic, Z. and Miladinovic, L. (2014) Method of Evaluating the Impact of ERP Implementation Critical Success Factors-A Case study in Oil and Gas Industries. Enterprise Information Systems, 8, 84-106. http://dx.doi.org/10.1080/17517575.2012.690105

[9] Warfield, J.N. (2007) Systems Science Serves Enterprise Integration: A Tutorial. Enterprise Information Systems, 1, 235-254. http://dx.doi.org/10.1080/17517570701241079

[10] Wan, J.P. and Jones, J.D. (2013) Managing IT Service Management Implementation Complexity: From the Perspective of the Warfield Version of Systems Science. Enterprise Information Systems, 7, 490-522. http://dx.doi.org/10.1080/17517575.2011.625572 